University of Nebraska - Lincoln

DigitalCommons@University of Nebraska - Lincoln

2012

\title{
Attendance Patterns and Survival of Western Meadowlark Nests
}

Larkin A. Powell

University of Nebraska-Lincoln, Ipowell3@unl.edu

Matthew D. Giovanni

University of Nebraska at Lincoln, matthewgiovanni@gmail.com

Scott R. Groepper

University of Nebraska-Lincoln, scott.groepper@yahoo.com

Mitchell Reineke

University of Nebraska-Lincoln, mitch.reineke@gmail.com

Walter H. Schacht

University of Nebraska-Lincoln, wschacht1@unl.edu

Follow this and additional works at: https://digitalcommons.unl.edu/natrespapers

Part of the Natural Resources and Conservation Commons

Powell, Larkin A.; Giovanni, Matthew D.; Groepper, Scott R.; Reineke, Mitchell; and Schacht, Walter H., "Attendance Patterns and Survival of Western Meadowlark Nests" (2012). Papers in Natural Resources. 360.

https://digitalcommons.unl.edu/natrespapers/360

This Article is brought to you for free and open access by the Natural Resources, School of at DigitalCommons@University of Nebraska - Lincoln. It has been accepted for inclusion in Papers in Natural Resources by an authorized administrator of DigitalCommons@University of Nebraska - Lincoln. 


\title{
Attendance Patterns and Survival of Western Meadowlark Nests
}

\author{
Larkin A. Powell, Matthew D. Giovanni. Scott Groepper. \\ Mitchell L. Reineke, and Walter H. Schacht
}

Abstract. Biologists have linked nest attendance and nestling feeding rates to nest predation risk. Patterns of nest attendance also influence the success of methods designed to find nests for research use, such as rope drags. Very little has been published with regard to variation of attendance during the nesting period, but advances in video nest monitoring allow continuous data collection to provide this information. Our objectives were to (1) document attendance patterns at Western Meadowlark (Sturnella neglecta) nests, (2) identify predator species of meadowlark nests, and (3) assess the effects of our camera system on nest survival. We used a solar-powered, digital video-recording system with infrared-capable cameras to monitor nests at the Gudmundsen Sandhills Laboratory in the Nebraska Sandhills during 2006. We assessed video from 10 meadowlark nests to record nest attendance data, and we monitored 37 additional meadowlark nests to estimate survival for nests without a camera observation system. Meadowlark females spent more time at the nest during incubation than during the nestling stage. The proportion of time absent did not vary among daytime temporal segments during either nest stage. Females were absent, as a proportion of time, 0.24 during the day and 0.04 during the night throughout incubation, and 0.66 and 0.13 , respectively, during the nestling stage. We documented three types of predators, and we found no evidence of negative effects of nest cameras on estimates of daily nest survival. The attendance patterns we observed may contribute to temporal trends observed in daily nest survival of grassland birds. Nest cameras are a tool that can effectively contribute information to benefit efforts to improve productivity of grassland birds.

Key Words: nest attendance, nest camera, nest survival, predator, Sturnella neglecta, Western Meadowlark. iologists have linked nest attendance to nest predation risk (reviewed by Lima 2009). Duncan Rastogi et al. (2006) reported that songbirds with greater nest attendance tended to have lower rates of daytime predation. Recent application of nonlinear models to examine effects of nest age on survival has provided evidence of varying predation risk during the nest cycle (Grant et al. 2005, Kerns et al. 2010, Post van der Burg et al. 2010). Giovanni (2009) reported

Powell, L. A., M. D. Giovanni, S. Groepper, M. L. Reineke, and W. H. Schact. 2012. Attendance patterns and survival of Western Meadowlark nests. Pp. 61-66 in C. A. Ribic, F. R. Thompson III, and P. J. Pietz (editors). Video surveillance of nesting birds. Studies in Avian Biology (no. 43), University of California Press, Berkeley, CA. 
lower survival immediately following hatch and during the nestling period for Western Meadowlarks (Sturnella neglecta) on our study site. Although biologists suggest that feeding activities and related absences from the nest may increase predation risk (Martin et al. 2000, Pietz and Granfors 2005), we lack documentation of variation in attendance for songbirds during the nesting cycle. Such information may help assess relative risk of predation (Lima 2009).

Patterns of nest attendance also influence the success of methods designed to find nests for research use. For example, the rope-drag method (Higgins et al. 1969, Martin and Geupel 1993) is designed to disturb and flush an adult off the nest to reveal its location. However, the method's success is conditional on an adult attending the nest at the time of disturbance. Gloutney et al. (1993) provided nest attendance data for six duck species during temporal periods of the day, and encouraged researchers to focus nest searching during times of high attendance. Lloyd and Martin (2005) conducted nest searches for a grassland bird during times when nest attendance was highest. Therefore, data for temporal patterns of nest attendance are needed for altricial songbirds in grassland systems.

Management of species of concern may benefit from information provided by nest cameras about the suite of predators influencing productivity (Pietz and Granfors 2000). Walker et al. (2008) suggested that low Mallard (Anas platyrhynchos) nest survival in our study region, the Nebraska Sandhills, may be a result of a rich predator community. In addition, advances in power sources (solar and battery cells) and high-capacity digital video recorders have potential to provide finescale temporal information to answer mechanistic questions for ornithologists. Sanders and Maloney (2002) suggested that video equipment be used for more than identification of nest predators. Although video recordings may provide valuable information, Richardson et al. (2009) cautioned biologists to consider the effects of nest cameras on data collected via video. The size and presence of camera systems, as well as the timing of video sampling during the nest period, have potential to bias the suite of nest predators and nest survival estimates. Our objectives were to (1) document attendance patterns of Western Meadowlark adults at nests, (2) identify predator species at meadowlark nests, and (3) assess effects of our nest cameras on nest survival.

\section{METHODS}

\section{Study Area}

We sampled Western Meadowlark (hereafter, "meadowlark") nests in the central Nebraska Sandhills (Sandhills) at the University of Nebraska-Lincoln's Gudmundsen Sandhills Laboratory $\left(42^{\circ} 4^{\prime} \mathrm{N}, 101^{\circ} 27^{\prime} \mathrm{W}\right.$; Grant, Hooker, and Cherry counties), which includes about 5,000 ha of upland prairie and about 500 ha of lowland wet meadows and stream corridor. The central Sandhills is semi-arid and receives approximately $50 \mathrm{~cm}$ of precipitation annually (Wilhite and Hubbard 1998). The topography of the central Sandhills is characterized by mostly linear dune formations averaging between 41 and $50 \mathrm{~m}$ in height (Swinehart 1998).

\section{Nest Monitoring}

We located meadowlark nests with the rope-drag method (Winter et al. 2003) during a concurrent study (Giovanni 2009) from May through July in 2006; we also added fortuitous discoveries of nests to our sample. We marked each nest and recorded its location. We opportunistically assigned nests to be monitored with nest cameras. We randomly assigned each of our three camera systems to our initial pool of nests. When a video-monitored nest failed, we moved the system to the next nest located by nest searching.

Our nest camera system was powered by a $12-\mathrm{V}$ gel battery, recharged by a $60-\mathrm{W}$ solar panel. We used a digital video recorder (Archos ${ }^{\circledR}$ AV340) coupled with a weatherproof, infrared-capable camera (Supercircuits ${ }^{\circledR}$ PC1841R; shell: $6 \mathrm{~cm}$ $\times 5 \mathrm{~cm} \times 5 \mathrm{~cm} ; 8$ LEDs) to capture video (30 fps) images during monitoring. We downloaded the digital files every two days and assessed the status of the nest by viewing the video feed on the recorder's LCD screen. The digital video recorder was kept a weatherproof case attached to a wheeled cart (Power Rover; Dixon Power Systems, Lincoln, NE) that supported the solar panel (Fig. 5.1). The solar panel shaded the case to prevent interior temperatures from causing electronic failures, and the case was equipped with a thermostat-regulated fan to provide additional ventilation. The power supply and recorder were connected to the camera with a 31-m cable, which minimized monitoring at the nest. We made an attempt to conceal the cable in vegetation, and 


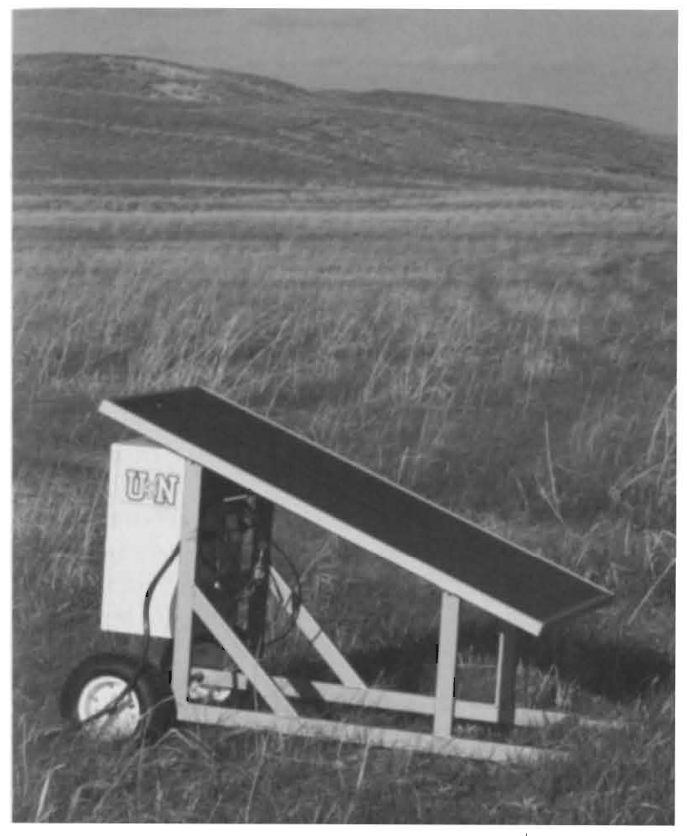

Figure 5.1. The solar power system used to support a digital video recorder, housed in the weatherproof case at left. Cables run $31 \mathrm{~m}$ from the power source and recorder to a camera at the nest. The system is shown on our study site during 2006 at the Gudmundsen Sandhills Laboratory in Grant, Hooker, and Cherry counties, Nebraska.

we enclosed our audio cables in a standard garden hose after initial tests resulted in small-mammal damage to the cable. The system could be deployed in $<5 \mathrm{~min}$. Nests without nest cameras were also monitored every two days.

\section{Analyses}

We transferred files from the DVR to a personal computer and used Microsoft ${ }^{\circledR}$ Windows Media Player to view video files from each nest. Nest attendance data were summarized in time-budget fashion, and we recorded the length of time that the following activities occurred at the nest: adult off nest (not in view), on nest incubating egg, on nest with nestlings, near nest (in view but not on nest, including fecal sac removal), and feeding nestlings. We also recorded parasitism events and predation events. We divided days into four temporal segments: morning (05:00-10:30 Mountain Daylight Time) mid-day (10:30-16:00), evening (16:00-21:30), and night (21:30-05:00). We based the segments on daylight and temperature (MayJuly sunrise: 05:11-05:43; sunset: 19:46-20:27;
U.S. Naval Observatory 2010). We summarized data in a spreadsheet for each individual by temporal segment, and we also lumped the three daytime periods (05:00-21:30) for other comparisons with data collected at night. We calculated the mean proportion, across individuals, for each nest activity, and established 95\% confidence intervals (CI) for each proportion.

We used Program MARK (ver. 6.1, Colorado State University, Ft. Collins, CO) to estimate daily nest survival (Dinsmore et al. 2002). We used AIC values, modified for small sample size $\left(\mathrm{AIC}_{\mathrm{c}}\right)$, to compare two models: a null model with constant survival across all nests, and a nest camera model, which allowed survival to vary between nests with and without cameras.

\section{RESULTS}

We obtained video from ten meadowlark nests and we monitored another 37 nests as controls. Nest failures and staggered entries into our sample affected the sample sizes that could be used for comparison of nest attendance during nest stages (incubation $n=9$, nestling $n=5$; sample sizes by nestling age were: day $1: n=2$, day $2-3: n=4$, day $4-10: n=5$, day $11: n=3$, day $12: n=1$ ).

Adult meadowlarks spent significantly more time at the nest during incubation (present: 0.76, 95\% CI: \pm 0.09$)$ than during the nestling stage (0.35, 95\% CI: \pm 0.15$)$. During the nestling stage, feeding $(0.51,95 \% \mathrm{CI}: \pm 0.29)$ and brooding $(0.47$, $95 \% \mathrm{CI}: \pm 0.30$ ) occupied a similar proportion of the adult's time when at the nest during the day. During incubation, the proportion of time adults were absent was 0.24 (95\% CI: \pm 0.08$)$ during the day and 0.04 (95\% CI: \pm 0.02$)$ during the night. During the nestling stage, absence increased to 0.66 (95\% CI: \pm 0.13$)$ during the day $(05: 00-$ 21:30) and 0.13 (95\% CI: \pm 0.07 ) during the night. Absence did not differ among temporal periods of the day during the incubation or nestling stage. Adults were observed feeding nestlings during the same proportion of time at the nest $(\sim 0.10)$ throughout the day (Fig. 5.2).

Nine of the ten nests (90\%) monitored with nest cameras failed, and 31 of the 37 control nests $(84 \%)$ failed. Our nest camera systems failed to capture four of the predation events because of hard disk drive capacity issues. However, we documented five nest predation events: two bullsnakes (Pituophis catenifer; 


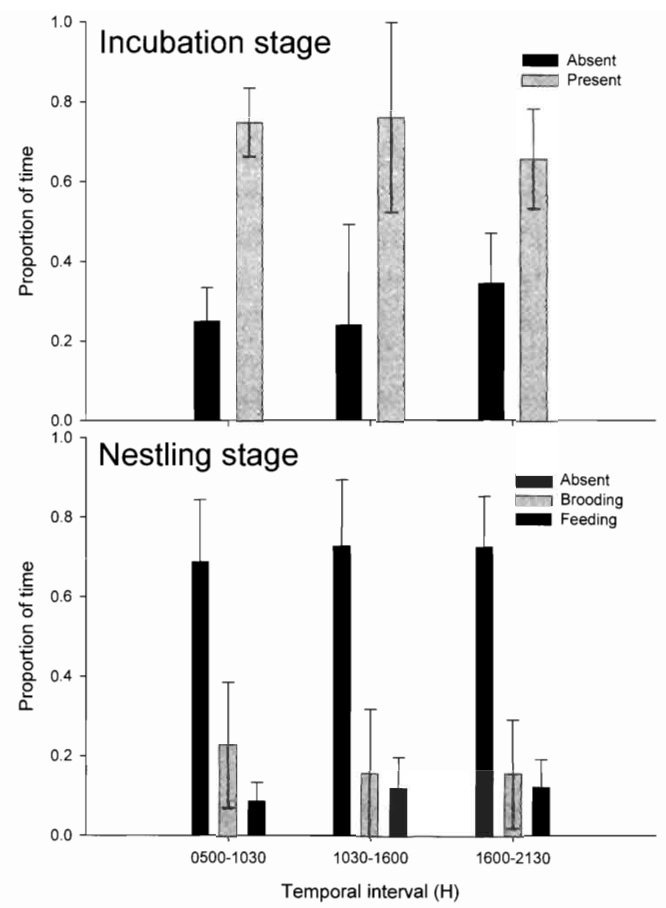

Figure 5.2. Proportion $( \pm 95 \%$ confidence intervals) of time during day that adults were absent from and present at Western Meadowlark nests during (a) incubation and (b) nestling stages during 2006 at the Gudmundsen Sandhills Laboratory in Nebraska. Observations are stratified by three temporal intervals during the day (05:00-21:30 Mountain Daylight Time): morning (05:00-10:30), mid-day (10:3016:00), and evening (16:00-21:30). Night observations are not shown. During the nestling stage, adult behaviors when present are divided between brooding and feeding activities.

nestling stage), two beetles (order Coleoptera; incubation stage), and a thirteen-lined ground squirrel (Ictidomys tridecemlineatus; incubation stage). In addition, we documented a meadowlark pecking and ingesting two meadowlark eggs at one nest.

Our sample provided no evidence to suggest that daily nest survival (DNS) varied between meadowlark nests with cameras (DNS: 0.903, $\mathrm{SE}=0.025,95 \% \mathrm{CI}: 0.842-0.941)$ and with out cameras (DNS: $0.887, \mathrm{SE}=0.019,95 \% \mathrm{CI}$ : $0.843-0.920$ ). The null model (no difference in nest survival) was ranked higher than the camera model (null: $\mathrm{AIC}_{\mathrm{c}}=165.5, w_{\mathrm{AICc}}=0.60$; camera model: $\mathrm{AIC}_{\mathrm{c}}=166.3, w_{\mathrm{AICc}}=0.40$ ). The nest survival estimates presented above are model-averaged estimates, with unconditional standard errors, because of uncertainty in model selection.

\section{DISCUSSION}

We found that Western Meadowlarks are absent from nests during large portions of the day and that adults were also away from the nest during significant portions of the night. Nest absence at night may be species-specific; Slay et al. (chapter 9, this volume) reported that Eastern Meadowlarks had relatively short duration of sleep between nighttime vigils, leaving the nest before sunrise to begin feeding their young. Data gathered by video is critical to enhance our knowledge of nighttime behaviors of nesting birds and nest predators.

The patterns of nest attendance that we observed between nest stages may contribute to temporal trends reported in daily nest survival of grassland birds (Davis 2005, Grant et al. 2005), including the higher risk of failure following hatching of meadowlarks on our study site (Giovanni 2009). Of course, the presence of nestlings in the nest may also contribute olfactory and auditory cues to predators, which coincides with this period of increased adult absence from the nest.

Our sample of video-monitored nests was inadequate to construct a complete list of nest predators for our study site. Our observation of beetles as nest predators is unique. We could find no video evidence that the beetles were scavenging an already failed nest. The beetles appeared to pierce an opening in the egg and continued to enlarge the opening and ingest contents. Our observation of a meadowlark depredating meadowlark eggs corresponds with previous evidence suggesting that meadowlarks may be common intra- and inter-specific predators of eggs (Creighton and Porter 1974, Schaeff and Picman 1988, Picman 1992). We were unable to document whether the individual was the attending parent of the nest, but anecdotal evidence of meadowlarks predating small passerine species also supports the notion that predatory behavior may be common (Schrick 1979, Bell 1990, Waters 1990).

A meta-analysis by Richardson et al. (2009) suggested that, on average, nest cameras may reduce the risk of predation at nests. Our survival rates tended to support that general trend, although we do not have strong evidence for higher daily survival rates at nests with cameras. Our sample of nests monitored by cameras is small, but our data suggest that nest cameras did not cause lower survival rates of nests at our study site. 
Renfrew and Ribic (2003) suggested that late deployments of nest cameras during the nest cycle may be responsible for the positive bias often observed in survival at nests with cameras. Our cameras, on average, were deployed after the initiation of incubation. However, our data suggests that increasing absences of adults during the nestling period should be expected to cause a negative bias, rather than positive, in such situations. Adults at the nest may serve to deter some small predators, such as thirteen-lined ground squirrels (Pietz and Granfors 2005). Giovanni's (2009) survival analyses, in which nest survival declined throughout the nest period, also suggest that late-placed nest cameras would actually negatively bias nest survival estimates because they are sampling the portion of the nest period with lowest survival. Thus, we propose that the neophobic reactions of some predators may be even stronger than Richardson et al. (2009) suggested if the reaction overcompensates for the negative bias imposed by late deployments of nest cameras. Regardless, we saw no evidence to suggest that our relatively large solar power system (Fig. 5.1) attracted predators to nests on our study site. We also found no evidence that the system served as a perch for Brownheaded Cowbirds (Molothrus ater) or territorial meadowlarks.

Our data suggest that adults are present at meadowlark nests at relatively constant rates throughout the day. Gloutney et al. (1993) used nest attendance rates of waterfowl to maximize nest detection during searching, but it appears that meadowlark nests are equally detectable throughout the day. Our attendance patterns were similar to those of Smith et al. (2009), who suggested that nests of shorebirds should be more detectable during the incubation period than during the nestling period. Thus, our data do provide pause for biologists who use rope-dragging to estimate nest density. Recently, Renfrew et al. (2005) and McMaster et al. (2005) acknowledged assumptions of constant detection. Our data suggest that nests should be three times more likely to be found during the incubation stage than the nestling stage, assuming equal probabilities of flushing of an adult on the nest during each stage. Thus, we caution against the use of the rope-drag method to establish nest densities; methods that estimate stage-specific detectability rates should be investigated (Giovanni et al. 2011).
Breeding meadowlarks adjust their incubation, brooding, and food-provisioning rates in response to the environment and nest cycle progression. Nest cameras, such as the system we used, can increase the knowledge of dynamics occurring at the nest, which should benefit efforts to improve productivity of grassland birds.

\section{ACKNOWLEDGMENTS}

We thank the staff at Gudmundsen Sandhills Laboratory for logistical support. R. Byrnes and J. Soper helped find and monitor nests. SG was partially supported by an award from the University of NebraskaLincoln's (UNL) Undergraduate Creative Activities and Research Experience program. MDG was supported by an assistantship from the Department of Agronomy and Horticulture at UNL. This manuscript was improved by the comments of two anonymous reviewers. Funding was provided by the UNL Foundation's Burlington Northern Water Science Endowment, and this research was supported by Hatch Act funds through the University of Nebraska Agricultural Research Division, Lincoln, Nebraska.

\section{LITERATURE CITED}

Bell, P. 1990. Eastern Meadowlark predation on American Goldfinches. Bulletin of the Oklahoma Ornithological Society 23:20-22.

Creighton, P. D., and D. K. Porter. 1974. Nest predation and interference by Western Meadowlarks. Auk 91:177-178.

Davis, S. K. 2005. Nest-site selection patterns and the influence of vegetation on nest survival of mixedgrass prairie passerines. Condor 107:605-616.

Dinsmore, S. J., G. C. White, and F. L. Knopf. 2002. Advanced techniques for modeling avian nest survival. Ecology 83:3476-3488.

Duncan Rastogi, A., L. Zanette, and M. Clinchy. 2006. Food availability affects diurnal nest predation and adult antipredator behaviour in Song Sparrows, Melospiza melodia. Animal Behaviour 72:933-940.

Giovanni, M. D. 2009. Demographics and microhabitat selection for the Western Meadowlark (Sturnella neglecta) in the Nebraska Sandhills. Ph.D. dissertation, University of Nebraska-Lincoln, Lincoln, NE.

Giovanni, M. D., M. Post van der Burg, L. C. Anderson, L. A. Powell, W. H. Schacht, and A. J. Tyre. 2011. Estimating nest density when nest detectability is incomplete: variation in nest attendance and response to disturbance by adult Western Meadowlarks. Condor 113:223-232.

Gloutney, M. L., R. G. Clark, A. D. Afton, and G. J. Huff. 1993. Timing of nest searches for upland 
nesting waterfowl. Journal of Wildlife Management 57:597-601.

Grant, T. A., T. L. Shaffer, E. M. Madden, and P. J. Pietz. 2005. Time-specific variation in passerine nest survival: new insights for old questions. Auk 122:661-672.

Higgins, K. F., L. M. Kirsch, and I. J. Ball, Jr. 1969. A cable-chain device for locating duck nests. Journal of Wildlife Management 33:1009-1011.

Kerns, C. K., M. R. Ryan, R. K. Murphy, F. R. Thompson III, and C. S. Rubin. 2010. Factors affecting songbird nest survival in northern mixed-grass prairie. Journal of Wildlife Management 74:257-264.

Lima, S. L. 2009. Predators and the breeding bird: behavioral and reproductive flexibility under the risk of predation. Biological Reviews 84:485-513.

Lloyd, J. D., and T. E. Martin. 2005. Reproductive success of Chestnut-collared Longspurs in native and exotic grassland. Condor 107:363-374.

Martin, T. E., and G. R. Geupel. 1993. Nest-monitoring plots: methods for locating nests and monitoring success. Journal of Field Ornithology 64:507-519.

Martin, T. E., J. Scott, and C. Menge. 2000. Nest predation increases with parental activity: separating nest site and parental activity effects. Proceedings of the Royal Society of London, Series B 267:2287-2294.

McMaster, D. G., J. H. Devries, and S. K. Davis. 2005. Grassland birds nesting in hay lands of southern Saskatchewan: landscape influences and conservation priorities. Journal of Wildlife Management 69:211-221.

Picman, J. 1992. Egg destruction by Eastern Meadowlarks. Wilson Bulletin 104:520-525.

Pietz, P. J., and D. A. Granfors. 2000. Identifying predators and fates of grassland passerine nests using miniature video cameras. Journal of Wildlife Management 64:71-87.

Pietz, P. J., and D. A. Granfors. 2005. Parental nest defense on videotape: more reality than "myth." Auk 122:701-705.

Post van der Burg, M., L. A. Powell, and A. J. Tyre. 2010. Finding the smoothest path to success: model complexity and the consideration of nonlinear patterns in nest-survival data. Condor 112:421-431.

Renfrew, R. B., and C. A. Ribic. 2003. Grassland passerine nest predators near pasture edges identified on videotape. Auk 120:371-383.

Renfrew, R. B., C. A. Ribic, and J. L. Nack. 2005. Edge avoidance by nesting grassland birds: a futile strategy in a fragmented landscape. Auk 122:618-636.
Richardson, T. W., T. Gardali, and S. H. Jenkins. 2009. Review and meta-analysis of camera effects on avian nest success. Journal of Wildlife Management 73:287-293.

Sanders, M. D., and R. F. Maloney. 2002. Causes of mortality at nests of ground-nesting birds in the Upper Waitaki Basin, South Island, New Zealand: a 5-year video study. Biological Conservation 106:225-236.

Schaeff, C., and J. Picman. 1988. Destruction of eggs by Western Meadowlarks. Condor 90:935-937.

Schrick, M. P. 1979. Tree Sparrows killed and eaten by meadowlarks. Bulletin of the Oklahoma Ornithological Society 12:33-34.

Smith, P. A., J. Bart, R. B. Lanctot, B. J. McCaffery, and S. Brown. 2009. Probability of detection of nests and implications for survey design. Condor 111:414-423.

Swinehart, J. B. 1998. Wind-blown deposits. Pp. 43-56 in A. S. Bleed and C. A. Flowerday (editors), An atlas of the Sand Hills. Conservation and Survey Division, Institute of Agriculture and Natural Resources, University of Nebraska, Lincoln, NE.

U.S. Naval Observatory. 2010. Hyannis, Nebraska rise and set for the sun. Astronomical Applications Department, U.S. Naval Observatory, Washington, DC. <http://www.usno.navy.mil/USNO/astronomicalapplications/data-services/rs-one-year-us $>$ (26 July 2010).

Walker, J. A., Z. J. Cunningham, M. P. Vrtiska, S. E. Stephens, and L. A. Powell. 2008. Low reproductive success of Mallards in the sandhills of Nebraska. Prairie Naturalist 40:1-15.

Waters, L. S. 1990. Meadowlarks prey on Pine Siskins and American Goldfinch. Bulletin of the Oklahoma Ornithological Society 23:7-8.

Wilhite, D. A., and K. G. Hubbard. 1998. Climate. Pp. 17-28 in A. S. Bleed and C. A. Flowerday (editors), An atlas of the Sand Hills. Conservation and Survey Division, Institute of Agriculture and Natural Resources, University of Nebraska, Lincoln, NE.

Winter, M., S. E. Hawks, J. A. Shaffer, and D. H. Johnson. 2003. Guidelines for finding nests of passerine birds in tall grass prairie. Prairie Naturalist 35:196211. 